\title{
The dosimetric impact of replacing the TG-43 algorithm by model based dose calculation for liver brachytherapy
}

\author{
Anna Sophie Duque ${ }^{1,2}$ DD, Stefanie Corradini ${ }^{1}$, Florian Kamp ${ }^{1}$, Max Seidensticker $^{3}$, \\ Florian Streitparth ${ }^{3}$, Christopher Kurz ${ }^{1,2}$, Franziska Walter ${ }^{1}$, Katia Parodi ${ }^{2}$, Frank Verhaegen ${ }^{4}$, \\ Jens Ricke ${ }^{3}$, Claus Belka ${ }^{1,5}$, Gabriel Paiva Fonseca ${ }^{4 \dagger}$ and Guillaume Landry ${ }^{1,2^{*} \dagger}$
}

\begin{abstract}
Purpose: To compare treatment plans for interstitial high dose rate (HDR) liver brachytherapy with ${ }^{192}$ Ir calculated according to current-standard TG-43U1 protocol with model-based dose calculation following TG-186 protocol. Methods: We retrospectively evaluated dose volume histogram (DVH) parameters for liver, organs at risk (OARs) and clinical target volumes (CTVs) of 20 patient cases diagnosed with hepatocellular carcinoma (HCC) or metastatic colorectal cancer (mCRC). Dose calculations on a homogeneous water geometry (TG-43U1 surrogate) and on a computed tomography (CT) based geometry (TG-186) were performed using Monte Carlo (MC) simulations. The CTs were segmented based on a combination of assigning TG-186 recommended tissues to fixed Hounsfield Unit (HU) ranges and using organ contours delineated by physicians. For the liver, $V_{5 G y}$ and $V_{10 G y}$ were analysed, and for OARs the dose to 1 cubic centimeter $\left(D_{1 c c}\right)$. Target coverage was assessed by calculating $V_{150}, V_{100}, V_{95}$ and $V_{90}$ as well as $D_{95}$ and $D_{90}$. For every DVH parameter, median, minimum and maximum values of the deviations of TG-186 from TG-43U1 were analysed.
\end{abstract}

Results: TG-186-calculated dose was found to be on average lower than dose calculated with TG-43U1. The deviation of highest magnitude for liver parameters was $-6.2 \%$ of the total liver volume. For OARs, the deviations were all smaller than or equal to -0.5 Gy. Target coverage deviations were as high as $-1.5 \%$ of the total CTV volume and $-3.5 \%$ of the prescribed dose.

Conclusions: In this study we found that TG-43U1 overestimates dose to liver tissue compared to TG-186. This finding may be of clinical importance for cases where dose to the whole liver is the limiting factor.

Keywords: Radiotherapy, Interstitial liver brachytherapy, HDR Ir-192 brachytherapy, Model-based dose calculation algorithm, Monte Carlo simulation, TG43, TG186

\section{Background}

Since the publication of the report of the American Association of Physicists in Medicine's (AAPM) Task Group (TG) 186 [1], which advocates the use of modelbased dose calculation (MBDC) as replacement to the

\footnotetext{
*Correspondence: Guillaume.Landry@med.uni-muenchen.de

${ }^{\dagger}$ Gabriel Paiva Fonseca and Guillaume Landry are equally contributing senior authors.

'Department of Radiation Oncology, University Hospital, LMU Munich,

Marchioninistraße 15, 81377 Munich, Germany

${ }^{2}$ Department of Medical Physics, Faculty of Physics,

Ludwig-Maximilians-Universität München, Am Coulombwall 1, 85748 Garching, Germany

Full list of author information is available at the end of the article
}

water kernel superposition algorithm recommended by the AAPM's TG-43U1 [2], there has been a concerted effort to identify brachytherapy treatment sites necessitating more sophisticated dose calculations. Treatment sites analysed so far include prostate [3], breast [4-7], head and neck [8], esophagus [6] and gynecologic regions $[6,9,10]$. To our knowledge there are no studies on the effect of MBDC for liver brachytherapy. MBDC make use of tissue composition and mass density as estimated from $x$-ray computed tomography (CT) images of the patient to account for differential attenuation, scattering and absorption between tissues. An important application of MBDC is also applicator modelling [1]. Algorithms for

(c) The Author(s). 2020 Open Access This article is distributed under the terms of the Creative Commons Attribution 4.0 International License (http://creativecommons.org/licenses/by/4.0/), which permits unrestricted use, distribution, and reproduction in any medium, provided you give appropriate credit to the original author(s) and the source, provide a link to the Creative Commons license, and indicate if changes were made. The Creative Commons Public Domain Dedication waiver (http://creativecommons.org/publicdomain/zero/1.0/) applies to the data made available in this article, unless otherwise stated. 
MBDC of current interest for ${ }^{192}$ Ir brachytherapy include collapsed-cone point kernel superposition [11-13], gridbased Boltzmann solvers [14, 15] as well as reference Monte Carlo (MC) simulation [16]. Different treatment planning systems (TPS) have adopted some of the algorithms listed above $[13,17]$. In the context of ${ }^{192}$ Ir high dose rate (HDR) brachytherapy, the use of MBDC is particularly important for treatment sites in the vicinity of tissue/air or tissue/lung interfaces, and wherever variations of tissue density play an important role [1].

The treatment of liver malignancies by CT-guided HDR brachytherapy, where fluoroscopy-CT is employed for catheter insertion and three dimensional (3D) breath-hold $\mathrm{CT}$ for treatment planning, is associated with encouraging clinical results for liver metastases as well as hepatocellular carcinoma $[18,19]$. It serves as an alternative to traditional treatment methodologies such as stereotactic body radiation therapy (SBRT) [20-24], transarterial chemoembolization (TACE) $[25,26]$ and radiofrequency ablation (RFA) [27] for nonresectable tumours. At the hospital of the Ludwig-Maximilians-Universität München (LMU Munich), 196 patients were treated with interstitial brachytherapy for liver malignancies in 2018 , and coincidentally also in 2019.

The goal of this study was to assess whether MBDC are required for accurate dosimetry of liver brachytherapy given the organ's proximity to the lung, its higher density than water, and the proximity of organs at risks (OARs) such as the stomach or duodenum (in addition to healthy liver tissue). MBDC were retrospectively compared to TG-43U1 calculations for liver cancer cases treated with ${ }^{192}$ Ir HDR brachytherapy, by employing CTbased, gold-standard MC simulations performed with the AMIGOBrachy [28] platform. Dose volume histogram $(\mathrm{DVH})$ indices for the clinical target volume (CTV), for the OARs and for the whole liver were compared between TG-186 and TG-43U1 dose distributions.

\section{Materials and methods Clinical cases}

This study retrospectively evaluated 20 treatment plans of 18 patients ( 15 males and 3 females) who were diagnosed with either metastasized colorectal cancer (mCRC) or hepatocellular carcinoma (HCC) and were treated with interstitial CT-guided brachytherapy at the university hospital of the LMU Munich. The patients had one (10 cases) or multiple (10 cases) lesions in the liver. The total number of treated lesions was 41. CTVs showed a high variation in volume, from less than $1 \mathrm{~cm}^{3}$ up to about $280 \mathrm{~cm}^{3}$, and as a consequence the number of dwell positions per CTV ranged from less than 10 to 100 . Doses of 12, 15, 20 or 25 Gy were prescribed and administered in a single fraction. The cases were selected to ensure a high variety and even distribution of prescription doses, number of CTVs, OAR types and medical diagnosis. Furthermore, no unused catheters were present and at least one OAR was delineated for every case. Table 1 contains more detailed information about the patients' characteristics.

Prior to treatment, brachytherapy catheters were inserted under fluoroscopy-CT guidance and local anaesthesia using a Seldinger technique. To achieve accurate placement of a catheter, a hollow gauge needle was first placed inside the lesion, then a stiff angiography guide wire was inserted into the needle. An angiography sheath was then inserted over the guide wire and the brachytherapy catheter was thereafter inserted into the angiography sheath $[18,29]$.

After successful placement of the catheters, a contrastenhanced planning CT (SOMATOM Definition Edge, Siemens) was acquired using an end-of-exhale breathhold technique. Catheter reconstruction, treatment planning and dose optimization were performed with the Oncentra ${ }^{\circledR}$ Brachy treatment planning system (Elekta $\mathrm{AB}$, Stockholm, Sweden) which uses the dose calculation algorithm of the TG-43U1 protocol. For each case the CTVs were delineated, which correspond to the GTVs extended by a $0-1 \mathrm{~mm}$ margin. As there are few setup or motion uncertainties in brachytherapy, the planning target volume (PTV) is equal to the CTV. Furthermore, the whole liver and a set of OARs were contoured for clinical treatment planning, from which the most relevant were selected for analysis in this study. The stomach was the most frequent OAR (14 cases), followed by heart (8 cases), bowel and colon (7 cases), right kidney and duodenum (5 cases), esophagus (4 cases), bile duct ( 3 cases), and gall bladder ( 1 case). Table 1 lists the relevant OARs for each case.

Brachytherapy treatment was administered with an HDR afterloading system (Flexitron, Elekta AB, Stockholm, Sweden) using an ${ }^{192}$ Ir HDR source.

\section{MC simulations}

MC simulations were performed with MCNP6 (Monte Carlo n-Particle, version 1.0 [30]), which is integrated in the auxiliary software AMIGOBrachy [28]. A phase space source was used for calculation, validated in a previous study [31]. As a TG43-U1 surrogate, we employed an $\mathrm{MC}$ simulation with the whole patient geometry set to water $\left(D_{\mathrm{w}, \mathrm{w}}\right)$. We used this instead of the TG-43U1 dose from the clinical TPS to avoid introducing biases which could be caused by TPS-specific aspects such as TG43-U1 parameter interpolation or cable modelling. For assessing dose transported in medium and scored in water $\left(D_{\mathrm{w}, \mathrm{m}}\right)$ or scored in the medium itself $\left(D_{\mathrm{m}, \mathrm{m}}\right), \mathrm{MC}$ simulations were performed on a heterogeneous patient model (TG186) based on the CT geometry. The CT images were segmented using auxiliary software, AMIGOBrachy [28], 
Table 1 Clinical situation of the 18 patients analysed in this study

\begin{tabular}{|c|c|c|c|c|c|c|}
\hline Case index & Patient & Gender & Treated lesions & Diagnosis & pr. dose (Gy) & OARs \\
\hline $\mathrm{i}$ & 1 & $\mathrm{~m}$ & 3 & $\mathrm{mCRC}$ & 25 & esophagus, stomach \\
\hline ii & 2 & $\mathrm{~m}$ & 4 & $\mathrm{HCC}$ & 15 & bowel, esophagus, heart, kidney, stomach \\
\hline iii & 3 & $f$ & 3 & $\mathrm{mCRC}$ & 25 & bowel, kidney, stomach \\
\hline iv & 4 & $\mathrm{~m}$ & 3 & $\mathrm{mCRC}$ & 25 & bile duct, bowel, colon, stomach \\
\hline$v$ & 4 & $\mathrm{~m}$ & 1 & $\mathrm{mCRC}$ & 20 & colon, duodenum, kidney, stomach \\
\hline vi & 5 & m & 2 & $\mathrm{HCC}$ & 12 & colon, stomach \\
\hline vii & 6 & $\mathrm{~m}$ & 1 & $\mathrm{HCC}$ & 15 & heart, stomach \\
\hline viii & 7 & $\mathrm{~m}$ & 1 & $\mathrm{HCC}$ & 12 & bile duct, bowel, gall bladder, kidney \\
\hline ix & 8 & $\mathrm{~m}$ & 1 & $\mathrm{mCRC}$ & 25 & bile duct, colon, duodenum \\
\hline$x$ & 8 & $\mathrm{~m}$ & 1 & $\mathrm{mCRC}$ & 25 & heart, oesophagus, stomach \\
\hline$x i$ & 9 & $\mathrm{~m}$ & 1 & $\mathrm{HCC}$ & 15 & heart \\
\hline xii & 10 & $\mathrm{~m}$ & 1 & $\mathrm{HCC}$ & 12 & bowel, stomach \\
\hline xiii & 11 & $\mathrm{~m}$ & 3 & $\mathrm{mCRC}$ & 20 & bowel, duodenum, stomach \\
\hline xiv & 12 & $\mathrm{~m}$ & 1 & $\mathrm{mCRC}$ & 25 & colon, kidney \\
\hline$x v$ & 13 & $\mathrm{~m}$ & 1 & $\mathrm{mCRC}$ & 20 & bowel, duodenum, stomach \\
\hline$x v i$ & 14 & $\mathrm{~m}$ & 5 & $\mathrm{mCRC}$ & 25 & colon, duodenum, heart, stomach \\
\hline xvii & 15 & $f$ & 3 & $\mathrm{mCRC}$ & 20 & colon, stomach \\
\hline xviii & 16 & $\mathrm{~m}$ & 3 & $\mathrm{HCC}$ & 15 & heart \\
\hline xix & 17 & m & 2 & $\mathrm{mCRC}$ & 25 & esophagus, heart, stomach \\
\hline$x x$ & 18 & f & 1 & $\mathrm{mCRC}$ & 25 & heart \\
\hline
\end{tabular}

Patients 4 and 8 were treated twice with different treatment plans, so the total number of analysed cases was 20. Patients were diagnosed with either metastatic colorectal cancer (mCRC) or hepatocellular carcinoma (HCC). Prescription (pr.) doses ranged from 12 to 25 Gy. The last column lists the OARs which were considered for each case

to create voxel geometries consisting of 5 tissues (lung $(\rho$ $\left.=0.26 \mathrm{~g} / \mathrm{cm}^{3}\right)$, mean adipose tissue $\left(\rho=0.95 \mathrm{~g} / \mathrm{cm}^{3}\right)$, mean male soft tissue $\left(\rho=1.03 \mathrm{~g} / \mathrm{cm}^{3}\right)$, mean female soft tissue $\left(\rho=1.02 \mathrm{~g} / \mathrm{cm}^{3}\right)$, liver $\left(\rho=1.06 \mathrm{~g} / \mathrm{cm}^{3}\right)$, and cortical bone $\left.\left(\rho=1.92 \mathrm{~g} / \mathrm{cm}^{3}\right)\right)$, with compositions and densities recommended by TG-186 [1], and air $\left(\rho=0.0012 \mathrm{~g} / \mathrm{cm}^{3}\right)$. The segmentation was performed by assigning homogeneous densities corresponding to the tissues specified above to fixed Hounsfield Unit (HU) ranges (see Table 2). We chose to assign reference densities instead of densities derived from a CT calibration curve to account for variations in density in organs which contained contrast agent, since during the time period from $\mathrm{CT}$ acquisition to treatment administration the contrast agent concentration decreased in the patient. In every case the liver was

Table 2 Hounsfield Unit thresholds used for tissue segmentation

\begin{tabular}{ll}
\hline HU range & Assigned tissue \\
\hline-1024 to -900 & Air \\
-899 to -200 & Lung \\
-199 to 0 & Mean adipose tissue \\
0 to 200 & Mean male/female soft tissue \\
201 to 2000 & Cortical bone \\
\hline
\end{tabular}

overwritten with a homogeneous density and composition according to TG-186, using the delineated organ contours. Parts of certain OARs (heart, kidney) were initially misassigned due to a high concentration of contrast agent. In these cases, the affected voxels were overwritten with mean male/female soft tissue density and composition.

$\mathrm{MC}$ calculations were performed on an interpolated version of the CT grid. Voxel dimensions within transversal planes of the CT grid ranged from $0.61 \mathrm{~mm}$ to $0.98 \mathrm{~mm}$ for the different cases and were deemed small enough for direct adoption to the dose calculation grid of the simulation. CT slice resolution ranged from $2 \mathrm{~mm}$ to $3 \mathrm{~mm}$ and was interpolated to enable a dose grid slice resolution of $1 \mathrm{~mm}$. Dose values were approximated as collision kerma assuming charged particle equilibrium, so secondary electrons were not transported [32, 33]. Simulations were performed using a track length tally and adopting massenergy absorption coefficients $\left(\mu_{\mathrm{en}} / \rho\right)$ from the National Institute of Standards and Technology (NIST) [34] for either water $\left(D_{\mathrm{w}, \mathrm{m}}\right)$ or medium $\left(D_{\mathrm{m}, \mathrm{m}}\right)$ to convert photon energy fluence to collision kerma/dose. Calculations were performed using the ${ }^{192}$ Ir photon spectrum available from the National Nuclear Data Center [35]. The calculation method has been described in detail by Fonseca et al [28, 31 ] and was also used by several authors [36-38]. The dose 
was cut off at a maximum value of $200 \mathrm{~Gy}$ for better comparison with the TPS, which uses this cutoff as a standard. $\mathrm{MC}$ uncertainties for all cases were assessed by calculating the voxel-wise standard deviation of repeated MC simulations and determining its maximum value within the $30 \%$-isodose line (relative to prescription dose) for $D_{\mathrm{w}, \mathrm{w}}$ and $D_{\mathrm{w}, \mathrm{m}} . D_{\mathrm{m}, \mathrm{m}}$ uncertainties are of the same magnitude as $D_{\mathrm{w}, \mathrm{m}}$ uncertainties for the calculation method used in this study. We set the number of particles (up to $4 \times 10^{10}$ for the different cases) such that $D_{\mathrm{w}, \mathrm{w}}$ standard deviations within the $30 \%$-isodose line were all below $0.8 \%$ and $D_{\mathrm{w}, \mathrm{m}}$ standard deviations below $1.3 \%$. To analyse the influence of these uncertainties on DVH parameter estimation we repeated the simulation for case iv (chosen arbitrarily) after increasing the number of histories by a factor of 10 and compared the DVH parameters with the results for the original number of histories. This led to deviations in the DVH-parameters that were all smaller than $0.2 \%$ of the respective DVH parameter value and were therefore considered negligible.

\section{Dosimetric comparison}

To evaluate differences between TG-43U1 and TG-186 in terms of clinically relevant quantities, DVH parameters were calculated for the liver, OARs and CTVs. To assess liver toxicity, the fractional liver volumes receiving at least 5 Gy or 10 Gy were calculated $\left(V_{5 \mathrm{~Gy}}\right.$ and $V_{10 G y}$, respectively). For each OAR, the dose to 1 cubic centimeter $\left(D_{1 \mathrm{cc}}\right)$ was calculated. For the CTVs we considered the fractional volumes receiving at least $150 \%$, $100 \%, 95 \%$ or $90 \%$ of the prescribed dose $\left(V_{150}, V_{100}, V_{95}\right.$ and $V_{90}$, respectively), and the doses that were administered to $95 \%$ or $90 \%$ of the CTV volumes $\left(D_{95}\right.$ and $D_{90}$, respectively).

We determined for each DVH parameter the median, minimum and maximum values over all treatment plans, calculated with $D_{\mathrm{w}, \mathrm{w}}$. To analyse the deviations between TG43-U1 and TG-186 we considered the absolute difference of TG-186-calculated parameters from $D_{\mathrm{w}, \mathrm{w}}$. Median, minimum and maximum of these deviations were calculated. For liver and OARs, the DVH parameters were compared to clinical tolerance limits.

\section{Results}

We report the comparison of $D_{\mathrm{w}, \mathrm{w}}$ and $D_{\mathrm{w}, \mathrm{m}}$ in the following subsections, divided into liver, OAR and CTV DVH parameter analysis. All of the reported results were obtained by MC simulations. Tables with the values for $D_{\mathrm{m}, \mathrm{m}}$ were not included, since the results were similar to the comparison of $D_{\mathrm{w}, \mathrm{m}}$ and $D_{\mathrm{w}, \mathrm{w}}$ and thus do not provide additional insights. For completeness they can be found in the Appendix (Tables 6, 7 and 8).

For an easier comparison between parameters, we also included the deviations from TG-43U1 in percentage of the corresponding parameter value. The tables can be found in the Supplementary material (S1, S2 and S3).

\section{Liver dose}

As an assessment of the influence of TG-186 on DVH parameters for the liver, we report $D_{\mathrm{w}, \mathrm{w}}$-calculated parameters as well as the absolute difference between $D_{\mathrm{w}, \mathrm{m}}$ - and $D_{\mathrm{w}, \mathrm{w}}$-calculated parameters for $V_{5 \mathrm{~Gy}}$ and $V_{10 \mathrm{~Gy}}$ shown in Table 3 and Fig. 1a. The median of $D_{\mathrm{w}, \mathrm{w}}$ was well within clinical tolerance levels, the maximum values exceeded tolerances by a few percent for both $V_{5 \mathrm{~Gy}}$ and $V_{10 \mathrm{~Gy}}$. The values of $V_{5 \text { Gy }}$ and $V_{10 G y}$ showed a very high spread, ranging from a few percent to values above the tolerance limit. The deviations were most pronounced for $V_{5 \mathrm{~Gy}}$, ranging from $-0.05 \%$ to $-6.2 \%$. $V_{10 G y}$-deviations ranged from $-0.01 \%$ to $-1.7 \%$. The median deviation was $-0.8 \%$ for $V_{5 \text { Gy }}$ and $-0.2 \%$ for $V_{10 G y}$.

For the case with highest deviation (case ii, -6.2\%) the

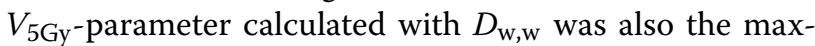
imum value of all cases, $72 \%$. It exceeded the tolerance of $67 \%$. With the reduction of $-6.2 \%$, the $D_{\mathrm{w}, \mathrm{m}}$-calculated value was just below the tolerance limit (66\%). The $V_{10 G y^{-}}$ parameter was also quite high (26\%), but did not exceed the tolerance of $33 \%$. For this value, the deviation was $1.7 \%$, which is also the deviation of highest magnitude over all cases for the $V_{10 \mathrm{~Gy}}$-parameter.

Figure 2 shows the dose distributions for this case and three other cases, calculated with $D_{\mathrm{w}, \mathrm{w}}$. For case i, the reduction of the $V_{5 \text { Gy }}$ when comparing $D_{\mathrm{w}, \mathrm{m}}$ to $D_{\mathrm{w}, \mathrm{w}}$ is clearly visible in the region between two CTVs. The liver is only partly covered by the 5 -Gy-isodose line. For case ii, the volume of the $D_{\mathrm{w}, \mathrm{m}}$-calculated 5-Gy-isodose is notably smaller than the $D_{\mathrm{w}, \mathrm{w}}$-calculated volume. Both cover a large part of the liver. This can also be seen in case iv, where $D_{\mathrm{w}, \mathrm{w}}$ and $D_{\mathrm{w}, \mathrm{m}}$ show a deviation close to the body surface. A large part of the liver is enclosed by the 5-Gy-isodose lines in this case. For case xix, the $D_{\mathrm{w}, \mathrm{w}^{-}}$ and $D_{\mathrm{w}, \mathrm{m}}$-isodose lines are quite close together, except at lung-tissue interface regions.

\section{OAR dose}

For the OARs we report the difference between $D_{\mathrm{w}, \mathrm{m}}$ and $D_{\mathrm{w}, \mathrm{w}}$ for $D_{1 \mathrm{cc}}$ of each OAR type (see Table 4 and Fig. $1 \mathrm{~b}$ ).

Table 3 Comparison of $D_{w, w}$ and $D_{w, m}$ for liver DVH parameters

\begin{tabular}{|c|c|c|c|c|c|c|c|}
\hline \multirow[t]{2}{*}{ Parameter (\%) } & \multicolumn{3}{|l|}{$D_{W, W}$} & \multicolumn{3}{|c|}{$D_{\mathrm{w}, \mathrm{m}}-D_{\mathrm{W}, \mathrm{w}}$} & \multirow[t]{2}{*}{ clin. tol } \\
\hline & Median & Min & Max & Median & Min & Max & \\
\hline$V_{5 G y}$ & 16 & 2 & 72 & -0.8 & -6.2 & -0.05 & 67 \\
\hline$V_{10 G y}$ & 7 & 1 & 38 & -0.2 & -1.7 & -0.01 & 33 \\
\hline
\end{tabular}

The total number of livers, equal to the total number of cases, was 20. All parameters are given in percentage of the total liver volume and correspond therefore to absolute deviations, not relative to the value of the DVH parameter. The last column shows clinical tolerance levels for the liver 


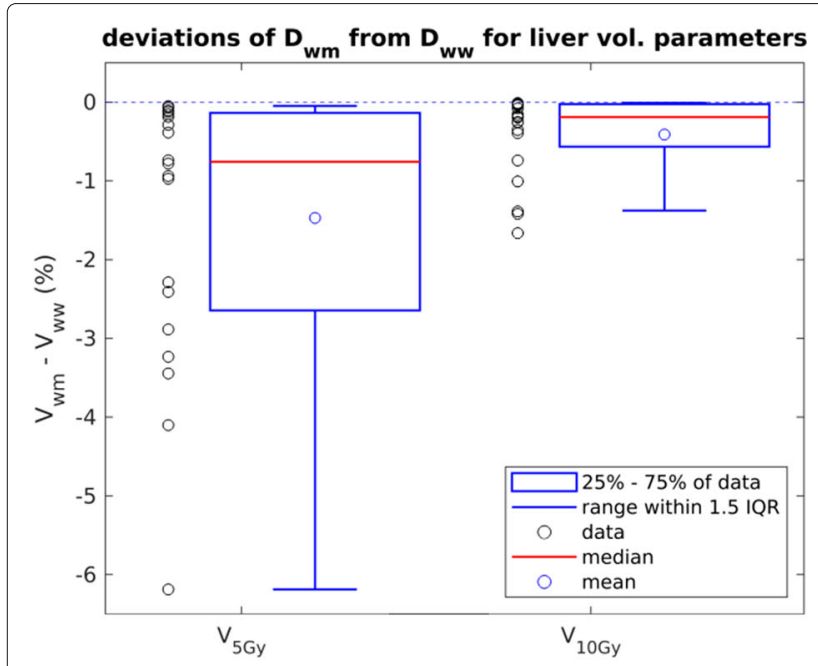

(a)

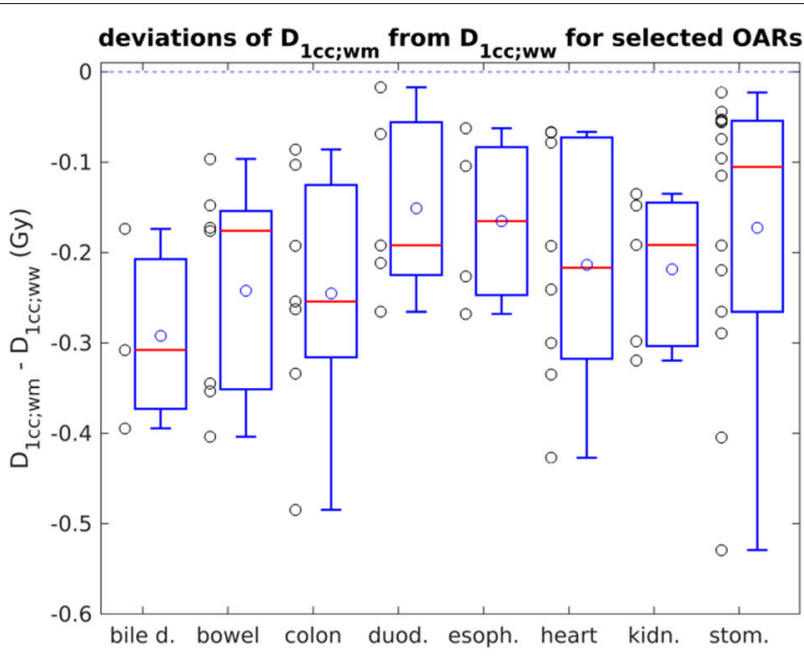

(b)

Fig. 1 Deviations of DVH parameters calculated with $D_{w, m}$ from $D_{w, w}$ for liver and OARs. IQR stands for interquartile range, which is equal to the spread of the central $50 \%$ of the data. a Deviations for liver parameters. b Deviations for selected OARs

The differences in $D_{1 \mathrm{cc}}$ ranged from $-0.02 \mathrm{~Gy}$ to $-0.5 \mathrm{~Gy}$. The median differences were of similar magnitude for all types of OAR. The highest deviations were found for colon $\left(-0.5 \mathrm{~Gy},-4.8 \%\right.$ relative to $D_{\mathrm{w}, \mathrm{w}}$-value) and stomach $\left(-0.5 \mathrm{~Gy},-3.7 \%\right.$ relative to $D_{\mathrm{w}, \mathrm{w}}$-value) of case iv.

The median $D_{\mathrm{w}, \mathrm{w}}$-values were within clinical tolerance limits for most OAR types. There was one case where the $D_{1 \mathrm{cc}}$ of the stomach exceeded the limit of 12 Gy both when calculated with $D_{\mathrm{w}, \mathrm{w}}(14.2 \mathrm{~Gy})$ and $D_{\mathrm{w}, \mathrm{m}}(13.7 \mathrm{~Gy})$.

\section{Target coverage}

Table 5 shows the values of the CTV DVH parameters, calculated for $D_{\mathrm{w}, \mathrm{w}}$, as well as deviations of $D_{\mathrm{w}, \mathrm{m}^{-}}$ calculated values from the latter. The deviations are also visualized in Fig. 3a and b. We observed little change for $V_{100}, V_{95}$ and $V_{90}$ when comparing $D_{\mathrm{w}, \mathrm{m}}$ and $D_{\mathrm{w}, \mathrm{w}}$, with the median deviation being $-0.05 \%$ for $V_{100},-0.02 \%$ for $V_{95}$ and $-0.01 \%$ for $V_{90}$. The most important deviation of these parameters was $-0.8 \%$. Figure 3a shows that most of the values are concentrated in a range of very low deviation with only a few exceptions. $V_{150}$ showed a higher deviation of $D_{\mathrm{w}, \mathrm{m}}$ from $D_{\mathrm{w}, \mathrm{w}}$ with a median of $-0.4 \%$ and a maximum deviation in absolute terms of $-1.5 \%$. $V_{150}$-deviations were more widely spread.

Concerning the dose parameters $D_{95}$ and $D_{90}$, the deviations from TG-43U1 had a median value of $-0.9 \%$ of the prescribed dose for $D_{95}$ and $D_{90}$. The deviations of largest magnitude were $-3.5 \%$ for $D_{95}$ and $-3.4 \%$ of the prescribed dose for $D_{90}$. For $D_{95}$, the maximum deviation was found to be $0.3 \%$ of the prescribed dose. Since this value corresponds to 0.07 Gy in absolute units, it is considered negligible. The maximum values of $D_{95}$ (256\% of the prescribed dose) and $D_{90}$ (302\% of the prescribed dose) corresponded to a case where two CTVs were located very close to one another which resulted in an accumulation of dose in that region.

\section{Discussion}

Our calculations found TG-186-calculated DVH-parameters to be in general lower than TG-43U1calculated parameters. This is in good agreement with the results of other groups who reported an overestimation of TG-43U1 in comparison to TG-186 for soft tissue in other tumour entities $[4,6,8,10]$. For breast cancer cases, Thrower et al. compared TG-43 to $D_{\mathrm{m}, \mathrm{m}}$ and reported relative percentage changes of $1.2 \%$ for $V_{100}, 0.86 \%$ for $V_{95}$ and $0.47 \%$ for $V_{90}$. Deviations in $D_{1 \text { cc }}$ were $3.1 \%$ for the rib, $2.5 \%$ for the skin and $3.1 \%$ for the lung [4]. Fotina et al. found a relative percentage change in target coverage of about $2 \%$ for breast, esophageal and gynecologic cases, comparing $D_{\mathrm{w}, \mathrm{m}}$ to TG-43 [6]. Peppa et al. reported changes when comparing $D_{\mathrm{m}, \mathrm{m}}$ to TG-43 of up to $2 \%$ relative to the prescription dose for head and neck cancer. Regarding target coverage, relative deviations were as high as $9.1 \%$ for $V_{200}$ and $5.2 \%$ for $V_{150}$ [8]. For cervix cancer patients, Jacob et al. compared TG-43 to $D_{\mathrm{m}, \mathrm{m}}$ and reported changes in target coverage parameter $D_{90}$ of $2.6 \%$, with similar values for $D_{95}$ and $D_{100}$. They found an average relative change of $2.8 \%$ in $D_{1 \mathrm{cc}}$ for rectum, bladder and sigmoid [10].

We decided to focus on $D_{\mathrm{w}, \mathrm{m}}$-values in the comparison to $D_{\mathrm{w}, \mathrm{w}}$, since $D_{\mathrm{m}, \mathrm{m}}$-values were very similar to $D_{\mathrm{w}, \mathrm{m}}$. This was expected for soft tissues in the range of ${ }^{192} \mathrm{Ir}$ - 

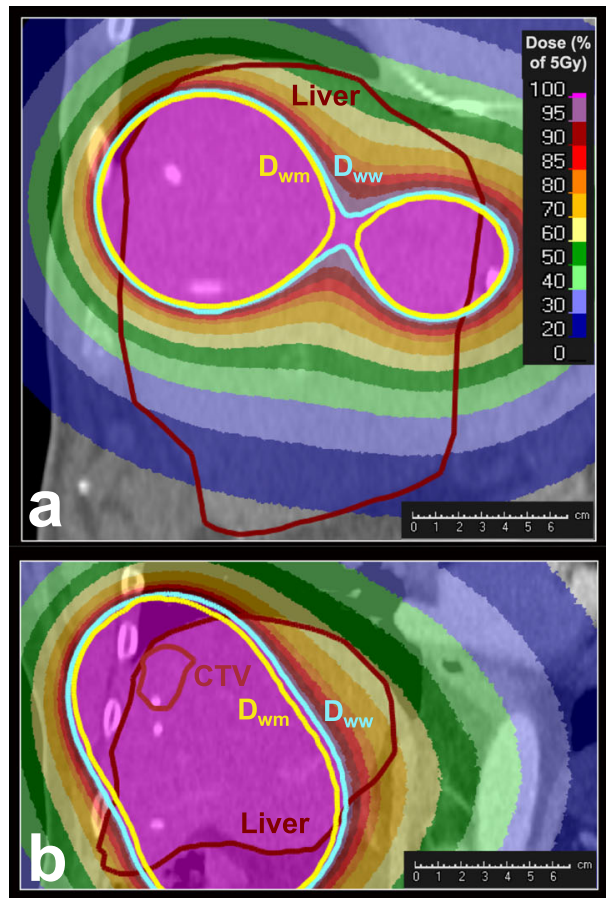

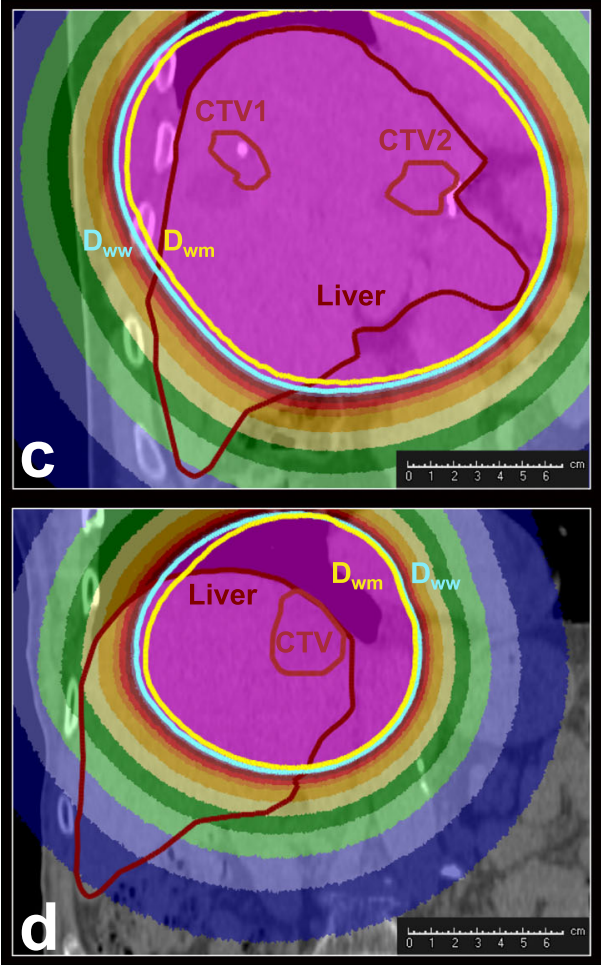

Fig. 2 Dose distributions of $D_{w, w}$ for coronal slices of 4 different cases. The dose profile is normalised so that $100 \%$ dose equals $5 \mathrm{~Gy}$. Overlaid are the contours of the 5-Gy-isodose lines of $D_{w, w}$ (light blue) and $D_{w, m}$ (yellow). Additional contours show the liver (dark red) and one or more CTVs (red). This figure focuses on the analysis of the $V_{5 \mathrm{~Gy}}$ parameter and is not suitable for evaluation of target coverage, since the CTVs are not always shown. a case i. b case ii. $\mathbf{c}$ case iv. $\mathbf{d}$ case xix
Table 4 Comparison of $D_{w, w}$ and $D_{w, m}$ for $D_{1 c c}$ of the selected OARs

\begin{tabular}{|c|c|c|c|c|c|c|c|}
\hline \multirow{2}{*}{ OAR } & \multirow{2}{*}{ Count } & \multicolumn{2}{|c|}{$D_{1 c c ; w, w}(G y)$} & \multicolumn{3}{|c|}{$D_{1 c c ; w, m}-D_{1 c c ; w, w}(G y)$} & \multirow{2}{*}{ - clin. tol. (Gy) } \\
\hline & & Mediar & Min Max & Mediar & Min & Max & \\
\hline Bile duct & 3 & 12.9 & 10.416 .5 & -0.3 & -0.4 & -0.2 & 21 \\
\hline Bowel & 7 & 8.0 & 4.813 .2 & -0.2 & -0.4 & -0.1 & 15 \\
\hline Colon & 7 & 5.7 & 2.612 .0 & -0.3 & -0.5 & -0.1 & 20 \\
\hline Duodenum & 5 & 7.1 & 1.47 .8 & -0.2 & -0.3 & -0.02 & 12 \\
\hline Esophagus & 4 & 5.3 & $3.0 \quad 7.7$ & -0.2 & -0.3 & -0.1 & 12 \\
\hline Gall bladder & 1 & 11.5 & - & -0.3 & - & - & 20 \\
\hline Heart & 8 & 9.0 & 2.713 .5 & -0.2 & -0.4 & -0.1 & 22 \\
\hline Kidney & 5 & 17.4 & 8.722 .5 & -0.2 & -0.3 & -0.1 & - \\
\hline Stomach & 14 & 8.0 & 1.614 .2 & -0.1 & -0.5 & -0.02 & 12 \\
\hline
\end{tabular}

The list of OARs for each case can be found in Table 1. The number of cases containing each OAR is listed in column 2. The last column shows clinical tolerance levels for the OARs. For kidney, the $D_{1 c c}$ is not a parameter that is used in clinical practice, therefore there is no tolerance level for this organ. All parameters are given in Gy

energies [1] and will therefore not be further addressed in this study.

\section{Liver dose}

The deviations of the $V_{5 \mathrm{~Gy}}$ - and $V_{10 \mathrm{~Gy}}$-parameter are of a magnitude that may be clinically relevant, especially $V_{5 \mathrm{~Gy}}$ shows large differences between $D_{\mathrm{w}, \mathrm{w}}$ and $D_{\mathrm{w}, \mathrm{m}}$. Since deviations differed strongly from case to case, we tried to find a case-specific feature determining the magnitude of deviation. As a first attempt, we looked at the dependence of deviations on the $V_{5 \mathrm{~Gy}}$-parameter. This volume was usually very large compared to other volume parameters $\left(V_{95}, V_{90}\right)$ resulting in a large travel distance for photons through the liver. Since liver density is higher than water density, photons do not travel as far as in water, and the $D_{\mathrm{w}, \mathrm{m}}$-isodose line is pulled back in comparison to $D_{\mathrm{w}, \mathrm{w}}$. This effect should be more pronounced for higher values

Table 5 Comparison of $D_{\mathrm{w}, \mathrm{w}}$ and $D_{\mathrm{w}, \mathrm{m}}$ for CTV DVH parameters

\begin{tabular}{lllllllll}
\hline Parameter (\%) & \multicolumn{1}{l}{$D_{\mathrm{w}, \mathrm{w}}$} & & & \multicolumn{2}{c}{$D_{\mathrm{w}, \mathrm{m}}-D_{\mathrm{w}, \mathrm{w}}$} \\
\cline { 2 - 3 } & Median & Min & Max & & Median & Min & Max \\
\hline$V_{150}$ & 85 & 67 & 100 & -0.4 & -1.5 & 0.05 \\
$V_{100}$ & 100 & 91 & 100 & -0.05 & -0.8 & 0.01 \\
$V_{95}$ & 100 & 93 & 100 & -0.02 & -0.7 & 0.03 \\
$V_{90}$ & 100 & 95 & 100 & -0.01 & -0.7 & 0 \\
$D_{95}$ & 123 & 90 & 256 & -0.9 & -3.5 & 0.3 \\
$D_{90}$ & 139 & 101 & 302 & -0.9 & -3.4 & 0.05 \\
\hline
\end{tabular}

The number of treated lesions for each case can be found in Table 1. The total number of treated lesions over all cases was 41 . All volume parameters are given in percentage of the total CTV volume, all dose parameters in percentage of the prescribed dose 


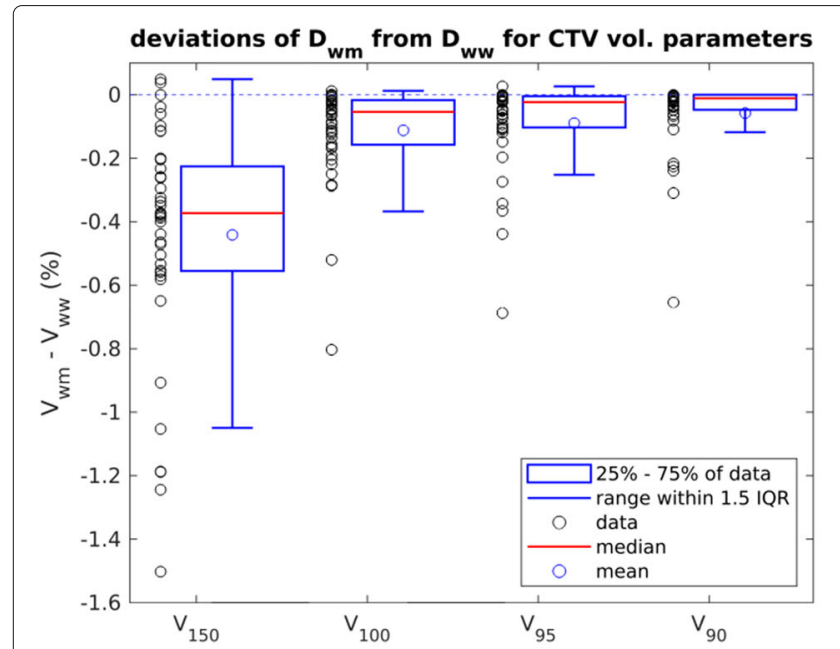

(a)

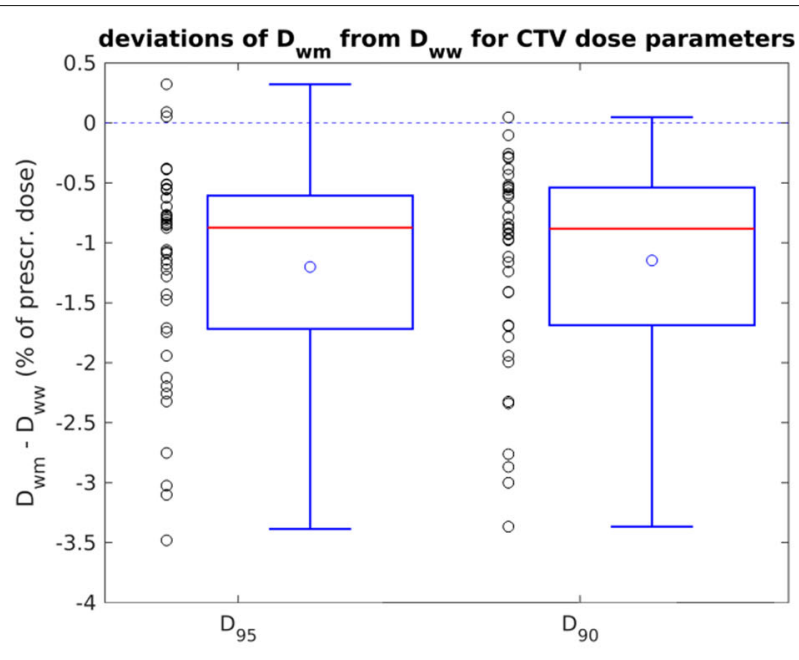

(b)

Fig. 3 Deviations of DVH parameters used to analyse target coverage. IQR stands for interquartile range, which is equal to the spread of the central $50 \%$ of the data. a Deviations of CTV volume parameters. b Deviations of CTV dose parameters

of the $V_{5 \mathrm{~Gy}}$-parameter due to an increase in photon travel distance.

To find correlations of the deviations of $V_{5 \mathrm{~Gy}}$ and the $V_{5 \text { Gy }}$-parameter itself, we plotted in Fig. 4 the relative deviations $\frac{V_{5 G \text { G;w, } \mathrm{m}}-V_{5 \mathrm{G} ; \mathrm{w}, \mathrm{w}}}{V_{5 \mathrm{~Gy} ; \mathrm{w}, \mathrm{w}}}$ over $V_{5 \mathrm{~Gy} ; \mathrm{w}, \mathrm{w}}$ in $\mathrm{cm}^{3}$. Since absolute deviations are expected to scale with $V_{5 \mathrm{~Gy} ; \mathrm{w}, \mathrm{w}}$, relative deviations are shown in this plot. Furthermore, since total liver volumes can vary a lot among patients, we show the $V_{5 \text { Gy }}$-parameter in absolute units of $\mathrm{cm}^{3}$ instead of percentages.

Due to a number of factors such as the large spread of prescription doses, the variation in number and size of CTVs and the location of CTVs, there is also a large spread in the values of the $V_{5 \mathrm{~Gy}}$-parameter. The plot shows that cases with a larger $V_{5 \mathrm{~Gy} ; \mathrm{w}, \mathrm{w}}$ tend to have relative deviations of larger magnitude. This tendency also explains why

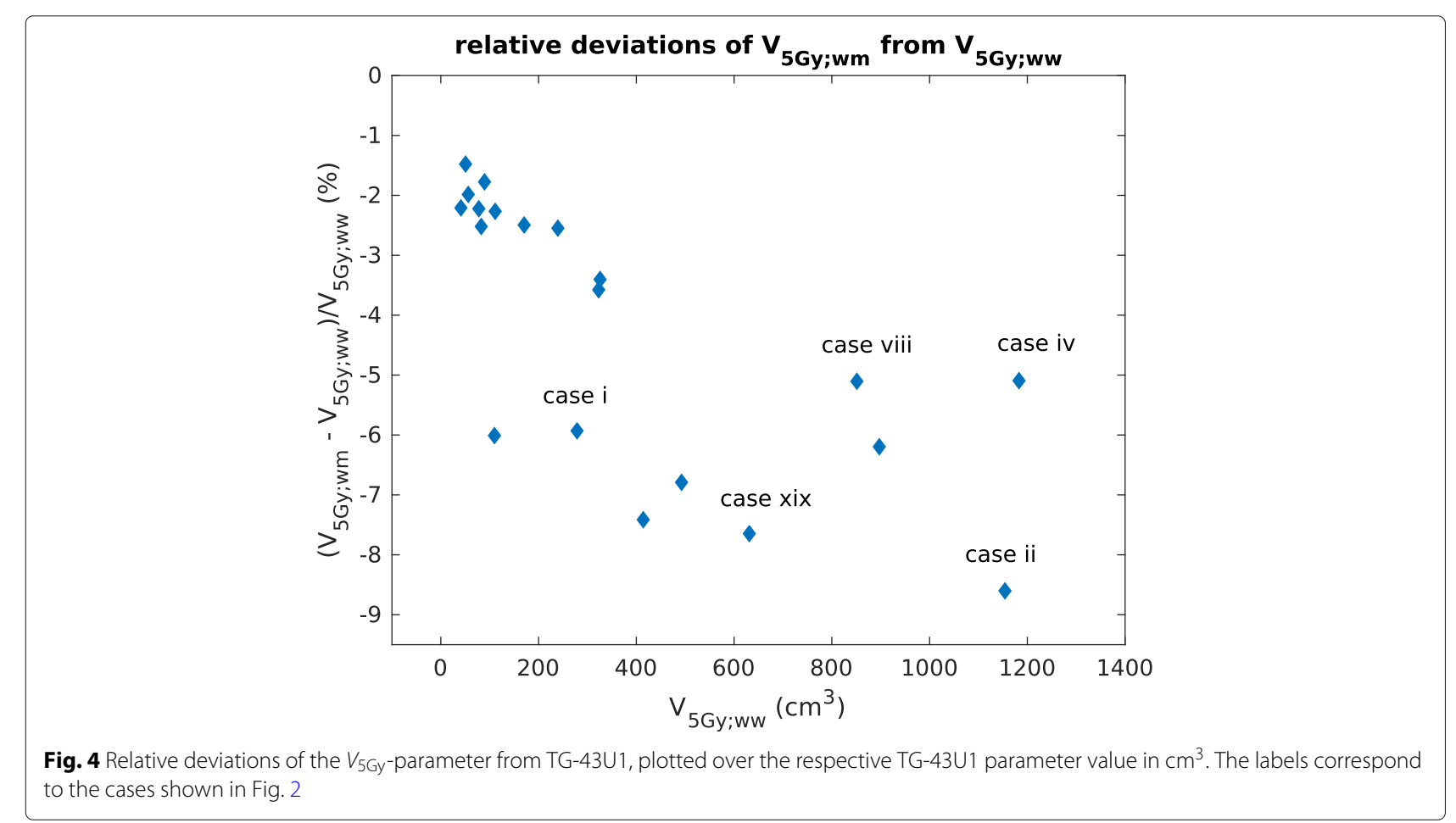


deviations of the $V_{10 G y}$-parameter, which is usually much smaller than the $V_{5 \mathrm{~Gy}}$-parameter, are also smaller in general. Cases marked in the plot correspond to those shown in Fig. 2. The effect of a higher $V_{5 \mathrm{~Gy}}$-volume on the separation of the two isodose lines is clearly visible when comparing case i (Fig. 2a) to the other cases (Fig. 2b-d), neglecting for case $i$ the region between the two CTVs where the separation of the isodose lines is larger.

Other groups also suggested a correlation between deviations from TG-43U1 and photon travel distance path. Thrower et al. and Zourari et al. found that deviations increased with increasing distance from dwell positions $[4,5]$ for breast cases, although in that case this was mostly due to lung heterogeneities.

Apart from a pure dependency on photon travel distance we also found other possible influences of the magnitude of the $V_{5 G y}$-parameter deviation. An example is case i: if we look at Fig. 2a, we see that this case had multiple treated CTVs (3 in total) and the dose in the overlap region between two CTVs was very close to 5 Gy. Since this region is fully enclosed by the liver, it has a high influence on the $V_{5 \mathrm{~Gy}}$-parameter deviation. This example shows that the number of source positions or CTVs per case may play a role in the magnitude of deviations of the $V_{5 \text { Gy }}$-parameter, given that the dose between CTVs is in the range of $5 \mathrm{~Gy}$ and the CTVs are not too close together.

Another influence on the $V_{5 \mathrm{~Gy}}$-parameter is shown in case iv (Fig. 2c). We can see that the $V_{5 \mathrm{~Gy}}$-volume is very large and only a smaller part of the liver is actually influenced by the deviations of $D_{\mathrm{w}, \mathrm{w}}$ and $D_{\mathrm{w}, \mathrm{m}}$. This example demonstrates that not only the magnitude of the $V_{5 \text { Gy }}$-parameter has an influence on the magnitude of the deviation from TG-43U1, but that also the location of the 5-Gy-isodose lines and therefore of the CTVs is important. If the isodose lines are located mostly inside of the liver, deviations will be much more pronounced than in cases like case iv, where most of the isodose lines are outside of the liver.

As can be seen in cases ii, iv and xix (Fig. 2b, c, d), proximity to lung, body surface or bone also has an influence on the 5-Gy-isodose. However, since sources are always placed inside the liver and only the percentage of the $V_{5 \mathrm{~Gy}}-$ volume that covers the liver is clinically relevant, these factors do not have a strong influence on the parameter itself. Only in cases where the 5-Gy-isodose line lies within the liver and at the same time close to a lung-tissue interface region (see Fig. 2d), loss of backscatter due to less photon attenuation in low-density tissue and therefore a reduction in $D_{\mathrm{w}, \mathrm{m}}$-dose is visible.

The data analysed in this study suggests that replacing TG-43U1 with TG-186 may be of clinical relevance if we look at typical parameters for the assessment of liver toxicity. There were a few cases where liver parameters were close to the tolerance limit. TG-186-calculated parameters showed a reduction in these parameters of up to $6.2 \%$ of the absolute liver volume. This result is important in clinical decision making regarding cases where a sufficient local tumour control can only be achieved by giving a relatively high dose to a large part of the liver. The wide spread of relative deviations for the $V_{5 \mathrm{~Gy}}$-parameter from a few percent up to almost $-9 \%$ (see Fig. 4) shows that there is a variety between cases that is not taken into account when only TG-43U1 is used for dose calculations. Studies have been performed on the tolerance of liver tissue to brachytherapy using radiation-induced liver damage (RILD) as a biological endpoint [39]. Our findings support a reassessment of current tolerance limits when computing dose following TG-186.

\section{OAR dose}

For the OARs, the deviations in absolute terms were small. There was one case (case iv) where the difference was -0.5 Gy for colon and for stomach. These organs were analysed in the CT images and a possible reason for increased deviations could be a larger distance from the brachytherapy source and therefore a reduction in dose because photons are travelling through liver tissue of higher density. However, this reduction is too small to have an impact on clinical treatment planning dose.

\section{Target coverage}

CTV volume parameters $V_{100}, V_{95}$ and $V_{90}$ show very small deviations from $D_{\mathrm{w}, \mathrm{w}}$ for most of the cases. This is primarily due to a very good coverage of the CTVs: For $V_{100}, V_{95}$ and $V_{90}$ the median value of $D_{\mathrm{w}, \mathrm{w}}$ was $100 \%$. Therefore, any deviations from TG-43U1 can hardly be seen in these parameters. $V_{150}$ has a median value of $85 \%$ and shows higher deviations from TG-43U1. This can be explained by the fact that this parameter was always located in a region of higher gradient of the DVH, where small deviations cause a major change of parameter value. These results agree with the findings of other groups who also reported an increase in deviations for $V_{150}$ compared to the other volume parameters [5, 8]. However, $V_{150}$ and $V_{100}$ are of little clinical relevance in brachytherapy for liver metastases, because there is no demand for a homogeneous dose profile in the target volumes. These parameters were mainly included for better comparison to other brachytherapy treatment sites such as breast, where they play an important role in determining plan quality.

The dose parameters $D_{95}$ and $D_{90}$ show slightly larger deviations than the volume parameters when comparing the percentage values. This can be explained by the fact that these values are located in the gradient of the DVH curve, and no longer in the plateau like most of the volume parameters. Still, these deviations are all well below $1 \mathrm{~Gy}$ and will therefore have no major influence on the target coverage. 
In this study we observed that the location and number of dwell positions as well as the liver volume are important parameters that influence the magnitude of deviations between TG-43U1 and TG-186, thus it may be interesting to systematically investigate their combined effect. For cases where doses to the whole liver are close to tolerance limits and where TG-186 dose is notably reduced compared to dose calculated by TG-43U1, a reassessment of tolerance doses may be beneficial. Further studies are needed to investigate this issue, since model-based dose calculations are not yet used as a standard in clinical practice.

The results of this study are limited by the tissue segmentation which only included 5 tissues. Furthermore, there was a high variety in number, size and location of CTVs, number and type of OARs and prescription doses, which makes a quantitative comparison between cases difficult.

Photon propagation through medium leads to modifications in the energy spectrum which increase with larger distance from the source. For ${ }^{192} \mathrm{Ir}$, modifications were found to be of a relevant magnitude in a previous study [31]. This can lead to errors in the conversion of $D_{\mathrm{w}, \mathrm{m}}$ to $D_{\mathrm{m}, \mathrm{m}}$ and vice versa. Since both of these properties were calculated on the fly in MCNP instead of employing any conversion factors, our results are not affected by these errors.

Since the liver is subject to a lot of intrafractional motion and treatment times can take up to $60 \mathrm{~min}$ [40], performing dose calculations on 4DCT data would be highly useful for estimating additional dose calculation errors due to motion. Respiratory motion has proven to have an impact on stereotactic ablative radiotherapy (SABR) plans for the treatment of hepatocellular carcinoma [41] due to the high magnitude of liver motion, which can exceed $5 \mathrm{~mm}$ even during usage of abdominal compression [42] and is different for different liver segments [43]. Another area of interest would be cases where the lung or parts of the bone, e.g. the thoracic wall, are considered to be OARs. Due to the highly different density compared to water these organs would supposedly be more sensitive to deviations of TG-186 from TG-43U1.

\section{Conclusion}

This study is to our knowledge the first one comparing TG-43U1 to TG-186 for the interstitial ${ }^{192}$ Ir HDR brachytherapy treatment of liver metastases and hepatocellular carcinoma. We found a general overestimation of DVH parameters by TG-43U1 compared to TG-186, especially regarding the liver $V_{5 \mathrm{~Gy}}$-parameter, of up to $6.2 \%$ of liver volume. Deviations from TG-43U1 regarding dose to OARs and target coverage were all well below $1 \mathrm{~Gy}$. We conclude that there may be a clinical benefit of reporting TG-186 alongside TG-43U1 for cases where differences between the calculation methods are high and doses to the whole liver are close to tolerance limits.

\section{Appendix}

Table 6 Comparison of $D_{w, w}$ and $D_{w, m}$ as well as $D_{w, w}$ and $D_{m, m}$ for liver DVH parameters

\begin{tabular}{|c|c|c|c|c|c|c|c|}
\hline \multirow[t]{2}{*}{ Parameter (\%) } & \multirow{2}{*}{$\frac{D_{\mathrm{w}, \mathrm{w}}}{\text { Median }}$} & \multicolumn{3}{|c|}{$D_{\mathrm{w}, \mathrm{m}}-D_{\mathrm{w}, \mathrm{w}}$} & \multicolumn{3}{|c|}{$D_{m, m}-D_{w, w}$} \\
\hline & & Median & Min & $\operatorname{Max}$ & Median & Min & $\operatorname{Max}$ \\
\hline$V_{5 G y}$ & 16 & -0.8 & -6.2 & -0.05 & -0.9 & -6.7 & -0.07 \\
\hline$V_{10 G y}$ & 7 & -0.2 & -1.7 & -0.01 & -0.2 & -1.9 & -0.02 \\
\hline
\end{tabular}

The total number of livers, equal to the total number of cases, was 20. All parameters are given in percentage of the total liver volume

Table 7 Comparison of $D_{w, w}$ and $D_{w, m}$ as well as $D_{w, w}$ and $D_{m, m}$ for $D_{1 c c}$ of the selected OARs

\begin{tabular}{|c|c|c|c|c|c|c|c|c|}
\hline \multirow[t]{2}{*}{$\overline{O A R}$} & \multirow[t]{2}{*}{ Count } & \multirow{2}{*}{$\frac{D_{1 \text { cciw,w }}(\mathrm{Gy})}{\text { Median }}$} & \multicolumn{3}{|c|}{$D_{1 c c, w, m}-D_{1 c c ; w, w}(G y)$} & \multicolumn{3}{|c|}{$D_{1 c c ; m, m}-D_{1 c c ;, w, w}(G y)$} \\
\hline & & & Median & Min & Max & Median & Min & $\operatorname{Max}$ \\
\hline Bile duct & 3 & 12.9 & -0.3 & -0.4 & -0.2 & -0.4 & -0.5 & -0.3 \\
\hline Bowel & 7 & 8.0 & -0.2 & -0.4 & -0.1 & -0.3 & -0.5 & -0.1 \\
\hline Colon & 7 & 5.7 & -0.3 & -0.5 & -0.09 & -0.3 & -0.9 & -0.1 \\
\hline Duodenum & 5 & 7.1 & -0.2 & -0.3 & -0.02 & -0.2 & -0.3 & -0.04 \\
\hline Esophagus & 4 & 5.3 & -0.2 & -0.3 & -0.06 & -0.2 & -0.3 & -0.1 \\
\hline Gall bladder & 1 & 11.5 & -0.3 & - & - & -0.4 & & - \\
\hline Heart & 8 & 9.0 & -0.2 & -0.4 & -0.07 & -0.3 & -0.6 & -0.1 \\
\hline Kidney & 5 & 17.4 & -0.2 & -0.3 & -0.1 & -0.3 & -0.5 & -0.2 \\
\hline Stomach & 14 & 8.0 & -0.1 & -0.5 & -0.02 & -0.2 & -0.6 & -0.07 \\
\hline
\end{tabular}

The list of OARs for each case can be found in Table 1. The number of cases containing each OAR is listed in column 2. All parameters are given in Gy

Table 8 Comparison of $D_{\mathrm{w}, \mathrm{w}}$ and $D_{\mathrm{w}, \mathrm{m}}$ as well as $D_{\mathrm{w}, \mathrm{w}}$ and $D_{\mathrm{m}, \mathrm{m}}$ for CTV DVH parameters

\begin{tabular}{|c|c|c|c|c|c|c|c|}
\hline \multirow[t]{2}{*}{ Parameter (\%) } & \multirow{2}{*}{$\frac{D_{w, w}}{\text { Median }}$} & \multicolumn{3}{|c|}{$D_{w, m}-D_{w, w}$} & \multicolumn{3}{|c|}{$D_{m, m}-D_{w, w}$} \\
\hline & & Median & Min & Max & Median & Min & Max \\
\hline$V_{150}$ & 85 & -0.4 & -1.5 & 0.05 & -0.8 & -2.0 & 0 \\
\hline$V_{100}$ & 100 & -0.05 & -0.8 & 0.01 & -0.1 & -1.1 & 0 \\
\hline$V_{95}$ & 100 & -0.02 & -0.7 & 0.03 & -0.06 & -1.0 & 0 \\
\hline$V_{90}$ & 100 & -0.01 & -0.7 & 0 & -0.02 & -0.9 & 0 \\
\hline$D_{95}$ & 123 & -0.9 & -3.5 & 0.3 & -1.9 & -4.4 & -0.8 \\
\hline$D_{90}$ & 139 & -0.9 & -3.4 & 0.05 & -1.8 & -4.4 & -1.0 \\
\hline
\end{tabular}

The number of treated lesions for each case can be found in Table 1. The total number of treated lesions over all cases was 41 . All volume parameters are given in percentage of the total CTV volume, all dose parameters in percentage of the prescribed dose 


\section{Supplementary information}

\section{Supplementary information accompanies this paper at} https://doi.org/10.1186/s13014-020-01492-9.

Additional file 1: Supplementary material.

\section{Abbreviations}

4DCT: Four-dimensional computed tomography; AAPM: American Association of Physicists in Medicine; CTV: Clinical target volume; CT: Computed tomography; $D_{1 c c}$ : Dose received by 1 cubic centimeter; $D_{95}$ : Dose received by $95 \%$ of the volume; $D_{90}$ : Dose received by $90 \%$ of the volume; $\mathrm{DVH}$ : Dose volume histogram; $D_{m, m}$ : Dose calculated and scored in medium; $D_{w, m}$ : Dose calculated in medium and scored in water; $D_{\mathrm{w}, \mathrm{w}}$ : Dose calculated and scored in water; Gy: Gray; HCC: Hepatocellular carcinoma; HDR: High dose rate; HU: Hounsfield Unit; IQR: Interquartile range; Ir: Iridium; mCRC: Metastatic colorectal cancer; MBDC: Model-based dose calculation; MC: Monte Carlo; MCNP: Monte Carlo n-Particle; OAR: Organ at risk; PTV: Planning target volume; RFA: Radiofrequency ablation; RILD: Radiation-induced liver damage; SABR: Stereotactic ablative radiotherapy; SBRT: Stereotactic body radiation therapy; TACE: Transarterial chemoembolization; TG: Task group; TPS: Treatment planning system; $V_{5 G y}$ : Volume receiving at least $5 \mathrm{~Gy} ; V_{10 G y}$ : Volume receiving at least $10 \mathrm{~Gy} ; V_{150}$ : Volume receiving at least $150 \%$ of the prescribed dose; $V_{100}$ : Volume receiving at least $100 \%$ of the prescribed dose; $V_{95}$ : Volume receiving at least $95 \%$ of the prescribed dose; $V_{90}$ : Volume receiving at least $90 \%$ of the prescribed dose

\section{Acknowledgements}

Not applicable.

\section{Authors' contributions}

ASD evaluated the Monte Carlo simulations, performed the statistical analysis and drafted the manuscript. SC supervised the study, collected clinical data and helped to draft the manuscript. FK collected clinical data, reviewed the manuscript and helped to finalize it. KP reviewed the manuscript and helped to finalize it. FV supervised the study, reviewed the manuscript and helped to finalize it. GPF participated in the design of the study, supervised it, performed the Monte Carlo simulations and helped to draft the manuscript. GL participated in the design of the study, supervised it, and helped to draft the manuscript. MS, FS, FW, CK, JR and CB reviewed the manuscript. All authors read and approved the final manuscript.

\section{Funding}

This work was supported by the DFG's Cluster of Excellence Munich-Centre for Advanced Photonics (MAP) and by the FöFoLe commission of the Medical Faculty of the LMU Munich under grant 1056

\section{Availability of data and materials}

The datasets supporting the conclusions of this article are included within the article.

\section{Ethics approval and consent to participate}

This retrospective study was exempt from requiring ethics approval. Bavarian state law (Bayrisches Krankenhausgesetz/Bavarian Hospital Law $\$ 27$ Absatz 4 Datenschutz (Dataprotection)) allows the use of patient data for research, provided that any person's related data are kept anonymous. German radiation protection laws request a regular analysis of outcomes in the sense of quality control and assurance, thus in the case of purely retrospective studies no additional ethical approval is needed under German law.

\section{Consent for publication}

Not applicable.

\section{Competing interests}

The Department of Radiation Oncology of the University Hospital of the LMU Munich has an ongoing brachytherapy research agreement with Elekta, Inc.

\section{Author details}

1 Department of Radiation Oncology, University Hospital, LMU Munich, Marchioninistraße 15, 81377 Munich, Germany. ${ }^{2}$ Department of Medical Physics, Faculty of Physics, Ludwig-Maximilians-Universität München, Am
Coulombwall 1, 85748 Garching, Germany. ${ }^{3}$ Klinik und Poliklinik für Radiologie, Klinikum der Universität München, Marchioninistraße 15, 81377 Munich, Germany. ${ }^{4}$ Department of Radiation Oncology (MAASTRO clinic), GROW School for Oncology and Developmental Biology, Maastricht University Medical Centre, Dr. Tanslaan 12,6229 ET Maastricht, The Netherlands. ${ }^{5}$ German Cancer Consortium (DKTK), Munich, Germany.

Received: 25 October 2019 Accepted: 13 February 2020

Published online: 09 March 2020

\section{References}

1. Beaulieu L, Carlsson Tedgren $\AA$, Carrier JF, Davis SD, Mourtada F, Rivard MJ, Thomson RM, Verhaegen F, Wareing TA, Williamson JF. Report of the Task Group 186 on model-based dose calculation methods in brachytherapy beyond the TG-43 formalism: Current status and recommendations for clinical implementation. Med Phys. 2012;39(10): 6208-36. https://doi.org/10.1118/1.4747264.

2. Rivard MJ, Coursey BM, DeWerd LA, Hanson WF, Saiful Huq M, Ibbott GS, Mitch MG, Nath R, Williamson JF. Update of AAPM Task Group No. 43 Report: A revised AAPM protocol for brachytherapy dose calculations. Med Phys. 2004;31(3):633-74.

3. Afsharpour H, D'Amours M, Coté B, Carrier J-F, Verhaegen F, Beaulieu L. A Monte Carlo study on the effect of seed design on the interseed attenuation in permanent prostate implants. Med Phys. 2008;35(8): 3671-81. https://doi.org/10.1118/1.2955754.

4. Thrower SL, Shaitelman SF, Bloom E, Salehpour M, Gifford K. Comparison of Dose Distributions With TG-43 and Collapsed Cone Convolution Algorithms Applied to Accelerated Partial Breast Irradiation Patient Plans. Int J Radiat Oncol Biol Phys. 2016;95(5):1520-6. https://doi. org/10.1016/j.jijrobp.2016.03.033.

5. Zourari K, Major T, Herein A, Peppa V, Polgár C, Papagiannis P. A retrospective dosimetric comparison of TG43 and a commercially available MBDCA for an APBI brachytherapy patient cohort. Phys Medica. 2015;31(7):669-76. https://doi.org/10.1016/j.ejmp.2015.05.010.

6. Fotina I, Zourari K, Lahanas V, Pantelis E, Papagiannis P. A comparative assessment of inhomogeneity and finite patient dimension effects in 60Co and 192Ir high-dose-rate brachytherapy. J Contemp Brachytherapy. 2018;10(1):73-84. https://doi.org/10.5114/jcb.2018.74327.

7. White SA, Landry G, van Gils F, Verhaegen F, Reniers B. Influence of trace elements in human tissue in low-energy photon brachytherapy dosimetry. Phys Med Biol. 2012;57(11):3585-96. https://doi.org/10.1088/ 0031-9155/57/11/3585.

8. Peppa V, Pappas E, Major T, Takácsi-Nagy Z, Pantelis E, Papagiannis P. On the impact of improved dosimetric accuracy on head and neck high dose rate brachytherapy. Radiother Oncol. 2016;120(1):92-97. https://doi. org/10.1016/j.radonc.2016.01.022.

9. Abe K, Kadoya N, Sato S, Hashimoto S, Nakajima Y, Miyasaka Y, Ito K, Umezawa R, Yamamoto T, Takahashi N, Takeda K, Jingu K. Impact of a commercially available model-based dose calculation algorithm on treatment planning of high-dose-rate brachytherapy in patients with cervical cancer. J Radiat Res. 2018;59(2):198-206. https://doi.org/10.1093/ $\mathrm{jrr} / \mathrm{rrx} 081$.

10. Jacob D, Lamberto M, DeSouza Lawrence L, Mourtada F. Clinica transition to model-based dose calculation algorithm: A retrospective analysis of high-dose-rate tandem and ring brachytherapy of the cervix. Brachytherapy. 2017;16(3):624-9. https://doi.org/10.1016/j.brachy.2017. 02.008 .

11. Terribilini D, Vitzthum V, Volken W, Frei D, Loessl K, van Veelen B, Manser P, Fix MK. Performance evaluation of a collapsed cone dose calculation algorithm for HDR Ir-192 of APBI treatments. Med Phys. 2017;44(10):5475-85. https://doi.org/10.1002/mp.12490.

12. Ahnesjö A. Collapsed cone convolution of radiant energy for photon dose calculation in heterogeneous media. Med Phys. 1989;16(4):577-92. https://doi.org/10.1118/1.596360.

13. Ma Y, Lacroix F, Lavallée M-C, Beaulieu L. Validation of the Oncentra Brachy Advanced Collapsed cone Engine for a commercial 1921r source using heterogeneous geometries. Brachytherapy. 2015;14:. https://doi. org/10.1016/j.brachy.2015.08.003.

14. Hofbauer J, Kirisits C, Resch A, Xu Y, Sturdza A, Pötter R, Nesvacil N. Impact of heterogeneity-corrected dose calculation using a grid-based 
Boltzmann solver on breast and cervix cancer brachytherapy. J Contemp Brachytherapy. 2016;8(2):143-9. https://doi.org/10.5114/jcb.2016.59352.

15. Vassiliev O, Wareing T, McGhee J, Failla G, Salehpour M, Mourtada F. Validation of a new grid-based Boltzmann equation solver for dose calculation in radiotherapy with photon beams. Phys Med Biol. 2010;55(3):581-98. https://doi.org/10.1088/0031-9155/55/3/002.

16. Rogers DWO. Fifty years of Monte Carlo simulations for medical physics. Phys Med Biol. 2006;51(13):287-301. https://doi.org/10.1088/0031-9155/ $51 / 13 / r 17$.

17. Krause F, Risske F, Bohn S, Delaperriere M, Dunst J, Siebert F-A. End-to-end test for computed tomography-based high-dose-rate brachytherapy. J Contemp Brachytherapy. 2018;10(6):551-8. https://doi. org/10.5114/jcb.2018.81026

18. Ricke J, Wust P. Computed Tomography-Guided Brachytherapy for Liver Cancer. Semin Radiat Oncol. 2011;21(4):287-93. https://doi.org/10.1016/j. semradonc.2011.05.005.

19. Kieszko D, CisekP, Kordzińska-Cisek I, Grzybowska-Szatkowska L. Treatment of hepatic metastases with computed tomography-guided interstitial brachytherapy. Oncol Lett. 2018;15(6):8717-22. https://doi.org/ 10.3892/ol.2018.8415.

20. Gerum S, Heinz C, Belka C, Walter F, Paprottka P, De Toni EN, Roeder F. Stereotactic body radiation therapy (SBRT) in patients with hepatocellular carcinoma and oligometastatic liver disease. Radiat Oncol. 2018;13(1): https://doi.org/10.1186/s13014-018-1048-4.

21. Hass P, Mohnike K, Kropf S, Brunner TB, Walke M, Albers D, Petersen C, Damm R, Walter F, Ricke J, Powerski M, Corradini S. Comparative analysis between interstitial brachytherapy and stereotactic body irradiation for local ablation in liver malignancies. Brachytherapy. 2019;18(6):823-8. https://doi.org/10.1016/j.brachy.2019.08.003.

22. Scorsetti M, Comito T, Clerici E, Franzese C, Tozzi A, Iftode C, Di Brina L, Navarria P, Mancosu P, Reggiori G, Fogliata A, Tomatis S, Torzilli G, Cozzi L. Phase II trial on SBRT for unresectable liver metastases: long-term outcome and prognostic factors of survival after 5 years of follow-up. Radiat Oncol. 2018;13(1):234. https://doi.org/10.1186/s13014-018-1185-9.

23. Mahadevan A, Blanck O, Lanciano R, Peddada A, Sundararaman S, D'Ambrosio D, Sharma S, Perry D, Kolker J, Davis J. Stereotactic Body Radiotherapy (SBRT) for liver metastasis - clinical outcomes from the international multi-institutional RSSearch ${ }^{\oplus}$ Patient Registry. Radiat Oncol. 2018;13(1):26. https://doi.org/10.1186/s13014-018-0969-2.

24. Gkika E, Schultheiss $M$, Bettinger D, Maruschke L, Neeff HP, Schulenburg M, Adebahr S, Kirste S, Nestle U, Thimme R, Grosu A-L, Brunner TB. Excellent local control and tolerance profile after stereotactic body radiotherapy of advanced hepatocellular carcinoma. Radiat Oncol. 2017;12(1):116.

25. Mohnike K, Steffen IG, Seidensticker M, Hass P, Damm R, Peters N, Seidensticker R, Schütte K, Arend J, Bornschein J, Streitparth T, Wybranski C, Wieners G, Stübs P, Malfertheiner P, Pech M, Ricke J. Radioablation by Image-Guided (HDR) Brachytherapy and Transarterial Chemoembolization in Hepatocellular Carcinoma: A Randomized Phase II Trial. Cardiovasc Intervent Radiol. 2019;42(2):239-49. https://doi.org/10. 1007/s00270-018-2127-5

26. Shiba S, Shibuya K, Katoh H, Kaminuma T, Miyazaki M, Kakizaki S, Shirabe K, Ohno T, Nakano T. A comparison of carbon ion radiotherapy and transarterial chemoembolization treatment outcomes for single hepatocellular carcinoma: a propensity score matching study. Radiat Oncol. 2019;14(1):137. https://doi.org/10.1186/s13014-019-1347-4.

27. Schnapauff D, Collettini F, Steffen I, Wieners G, Hamm B, Gebauer B, Maurer MH. Activity-based cost analysis of hepatic tumor ablation using CT-guided high-dose rate brachytherapy or CT-guided radiofrequency ablation in hepatocellular carcinoma. Radiat Oncol. 2016;11(1):1-9. https://doi.org/10.1186/s13014-016-0606-X.

28. Fonseca GP, Reniers B, Landry G, White S, Bellezzo M, Antunes PCG, de Sales $C P$, Welteman E, Yoriyaz H, Verhaegen F. A medical image-based graphical platform-Features, applications and relevance for brachytherapy. Brachytherapy. 2014;13(6):632-9. https://doi.org/10.1016/ j.brachy.2014.07.004.

29. Bretschneider T, Ricke J, Gebauer B, Streitparth F. Image-guided high-dose-rate brachytherapy of malignancies in various inner organs-technique, indications, and perspectives. J Contemp Brachytherapy. 2016;8(3):251-61. https://doi.org/10.5114/jcb.2016.61068.
30. Goorley T, James M, Booth T, Brown F, Bull J, Cox LJ, Durkee J, Elson J, Fensin M, Forster RA, Hendricks J, Hughes HG, Johns R, Kiedrowski B, Martz R, Mashnik S, McKinney G, Pelowitz D, Prael R, Sweezy J, Waters L, Wilcox T, Zukaitis T. Initial MCNP6 release overview. Nucl Technol. 2012;180(3):298-315. https://doi.org/10.13182/NT11-135.

31. Fonseca GP, Tedgren Å. C., Reniers B, Nilsson J, Persson M, Yoriyaz H, Verhaegen F. Dose specification for 192Ir high dose rate brachytherapy in terms of dose-to-water-in-medium and dose-to-medium-in-medium. Phys Med Biol. 2015;60(11):4565-79. https://doi.org/10.1088/0031-9155/ 60/11/4565.

32. Ballester F, Granero D, Ṕrez-Calatayud J, Melhus CS, Rivard MJ. Evaluation of high-energy brachytherapy source electronic disequilibrium and dose from emitted electrons. Med Phys. 2009;36(9): 4250-6. https://doi.org/10.1118/1.3194754.

33. Wang R, Li XA. Dose characterization in the near-source region for two high dose rate brachytherapy sources. Med Phys. 2002;29(8):1678-86. https://doi.org/10.1118/1.1493780.

34. Berger MJ, Hubbell JH, Seltzer SM, Chang J, Coursey JS, Sukumar R, Zucker DS, Olsen K. XCOM: Photon Cross Section Database (Version 1.3). 2005. https://www.nist.gov/pml/xcom-photon-cross-sections-database.

35. Baglin CM. Nuclear Data Sheets for $A=192$. Nucl Data Sheets. 2012 https://doi.org/10.1016/j.nds.2012.08.001.

36. Taylor REP, Rogers DWO. EGSnrc Monte Carlo calculated dosimetry parameters for 192Ir and 169Yb brachytherapy sources. Med Phys. 2008;35(11):4933-44. https://doi.org/10.1118/1.2987676.

37. Ma Y, Vijande J, Ballester F, Tedgren Å. C., Granero D, Haworth A, Mourtada F, Fonseca GP, Zourari K, Papagiannis P, Rivard MJ, Siebert FA, Sloboda RS, Smith R, Chamberland MJP, Thomson RM, Verhaegen F, Beaulieu L. A generic TG-186 shielded applicator for commissioning model-based dose calculation algorithms for high-dose-rate 192/r brachytherapy:. Med Phys. 2017;44(11):5961-76. https://doi.org/10.1002/ mp.12459.

38. Ballester F, Carlsson Tedgren $\AA$, Granero D, Haworth A, Mourtada F, Fonseca GP, Zourari K, Papagiannis P, Rivard MJ, Siebert FA, Sloboda RS, Smith RL, Thomson RM, Verhaegen F, Vijande J, Ma Y, Beaulieu L. A generic high-dose rate 192/r brachytherapy source for evaluation of model-based dose calculations beyond the TG-43 formalism. Med Phys. 2015;42(6):. https://doi.org/10.1118/1.4921020.

39. Seidensticker M, Burak M, Kalinski T, Garlipp B, Koelble K, Wust P, Antweiler K, Seidensticker R, Mohnicke K, Pech M, Ricke J. RadiationInduced Liver Damage: Correlation of Histopathology with Hepatobiliary Magnetic Resonance Imaging, a Feasibility Study. Cardiovasc Intervent Radiol. 2015;38:213-21. https://doi.org/10.1007/s00270-014-0872-7.

40. Lüdemann L, Wybranski C, Seidensticker M, Mohnike K, Kropf S, Wust P, Ricke J. In vivo assessment of catheter positioning accuracy and prolonged irradiation time on liver tolerance dose after single-fraction 192Ir high-dose-rate brachytherapy. Radiat Oncol. 2011;6(1):. https://doi. org/10.1186/1748-717X-6-107.

41. Gargett M, Haddad C, Kneebone A, Booth JT, Hardcastle N. Clinical impact of removing respiratory motion during liver SABR. Radiat Oncol. 2019;14(1):. https://doi.org/10.1186/s13014-019-1300-6.

42. Hu Y, Zhou YK, Chen YX, Zeng ZC. Magnitude and influencing factors of respiration-induced liver motion during abdominal compression in patients with intrahepatic tumors. Radiat Oncol. 2017;12(1):. https://doi. org/10.1186/s13014-016-0762-z.

43. Tsai YL, Wu CJ, Shaw S, Yu PC, Nien HH, Lui LT. Quantitative analysis of respiration-induced motion of each liver segment with helical computed tomography and 4-dimensional computed tomography. Radiat Oncol. 2018;13(1):59. https://doi.org/10.1186/s13014-018-1007-0.

\section{Publisher's Note}

Springer Nature remains neutral with regard to jurisdictional claims in published maps and institutional affiliations. 